\title{
Saúde e Espiritualidade: As Narrativas Profissionais na Estratégia Saúde da Família
}

\author{
Josué Barros Júnior ${ }^{1}$, Rayanne de Sousa Barbosa ${ }^{2}$, Raimundo Tavares de Luna Neto ${ }^{3 *}$, Natália Bastos Ferreira Tavares ${ }^{4}$, \\ Kerma Márcia de Freitas ${ }^{5}$, Cleciana Alves Cruz ${ }^{6}$, Úrsula Hérica dos Santos Moura ${ }^{7}$
}

\begin{abstract}
Resumo: Neste estudo objetivou-se analisar a percepção dos profissionais da Estratégia Saúde da Família sobre espiritualidade e saúde no cotidiano da atenção básica. Usou-se um estudo explicativo com abordagem qualitativa e o cenário utilizado foi a Estratégia Saúde da Família Cidade Nova, ICÓ-CE, os sujeitos da pesquisa foram 16 profissionais da ESF Cidade Nova, sendo eles Enfermeiros, Médicos, Técnicos de Enfermagem e Agentes Comunitários de Saúde. Observou-se que o cuidado espiritual ao paciente caracteriza um desafio subsidiado pela formação, maturidade, habilidade, serenidade e sensibilidade às reais necessidades do outro. Percebeu-se que a dimensão espiritual formará um novo paradigma social onde beneficiará a saúde integral da pessoa e capacitará o profissional a lidar com o paciente. Os profissionais, no geral, não estão preparados para prestar o cuidado espiritual aos pacientes, pois se necessita de uma implicação processual e pessoal de autoconhecimento e amadurecimento, uma experiência de fé significativa. Sendo assim, espera-se que esse estudo venha contribuir para a melhoria no atendimento e na qualidade de vida dos pacientes assistidos na unidade básica de saúde, trazendo novos conhecimentos, e mostrando a importância da espiritualidade inserida nesse contexto, no intuito de oferecer uma visão ampla aos profissionais nessa temática, trazendo benefícios para os mesmos e para os pacientes.
\end{abstract}

Palavras-Chave: Saúde. Espiritualidade. Estratégia Saúde da Família.

\section{Saúde e Espiritualidade: As Narrativas Profissionais na Estratégia Saúde da Família}

\begin{abstract}
Resumo: Neste estudo objetivou-se analisar a percepção dos profissionais da Estratégia Saúde da Família sobre espiritualidade e saúde no cotidiano da atenção básica. Usou-se um estudo explicativo com abordagem qualitativa e o cenário utilizado foi a Estratégia Saúde da Família Cidade Nova, ICÓ-CE, os sujeitos da pesquisa foram 16 profissionais da ESF Cidade Nova, sendo eles Enfermeiros, Médicos, Técnicos de Enfermagem e Agentes Comunitários de Saúde. Observou-se que o cuidado espiritual ao paciente caracteriza um desafio subsidiado pela formação, maturidade, habilidade, serenidade e sensibilidade às reais necessidades do outro. Percebeu-se que a dimensão espiritual formará um novo paradigma social onde beneficiará a saúde integral da pessoa e capacitará o profissional a lidar com o paciente. Os profissionais, no geral, não estão preparados para prestar o cuidado espiritual aos pacientes, pois se necessita de uma implicação processual e pessoal de autoconhecimento e amadurecimento, uma experiência de fé significativa. Sendo assim, espera-se que esse estudo venha contribuir para a melhoria no atendimento e na qualidade de vida dos pacientes assistidos na unidade básica de saúde, trazendo novos conhecimentos, e mostrando a importância da espiritualidade inserida nesse contexto, no intuito de oferecer uma visão ampla aos profissionais nessa temática, trazendo benefícios para os mesmos e para os pacientes.
\end{abstract}

Palavras-Chave: Saúde. Espiritualidade. Estratégia Saúde da Família.

\footnotetext{
1,2,5,6,7 Enfermeiro(as). Faculdade Vale do Salgado-FVS, Icó-Ce.

${ }^{3,4}$ Enfermeiro(a). Programa de Pós Graduação em Ciências da Saúde pela Faculdade de Medicina do ABC. Docente da Universidade Regional do Cariri (URCA) / Unidade Descentralizada de Iguatu-CE. Faculdade Vale do Salgado-FVS

* Autor correspondente: Raimundo Tavares de Luna Neto. Email: duquinhatavares@ gmail.com
} 


\section{Introdução}

A espiritualidade é definida como uma busca humana pelo significado da vida por meio de conceitos que transcendem o tangível: um sentido de conexão com algo maior que si próprio, que pode ou não incluir uma participação religiosa formal (SAAD et al., 2001; VOLCAN, 2003).

O termo espiritualidade refere-se a um amplo domínio da subjetividade humana, refletindo nos valores e ideais mais preciosos das pessoas, assim como o senso de quem são, as suas crenças, o significado e o propósito de suas vidas junto à conexão que elas estabelecem com os outros e com o mundo em que vivem. Sendo também incluída no meio pelo qual nós encontramos um sentido para tudo, além de esperança, conforto e paz interior em nossas vidas (KOENIG HG, 2010).

Na Resolução publicada de 07 de abril de 1999 a Organização Mundial da Saúde propõe incluir o âmbito espiritual no conceito multidisciplinar de saúde, que agrega, ainda, aspectos físicos, psíquicos e sociais. Crenças e experiências espirituais têm sido um dos componentes marcantes em diversas sociedades. Nesse contexto, a população em geral, profissionais de saúde e pesquisadores, tem reconhecido a importância da dimensão espiritual para a saúde (MOREIRA; ALMEIDA, 2011).

No cuidado em saúde desenvolvido na atenção básica, o Ministério da Saúde prioriza o desenvolvimento de ações através da Estratégia de Saúde da Família, que atuam numa visão de superação da antiga proposição de caráter exclusivamente centrado na doença, desenvolvendo-se por meio de práticas gerenciais e sanitárias, democráticas participativas e educativas, sob a forma de trabalho em equipe dirigido às populações de territórios delimitados (BRASIL, 2004).

Sendo as equipes de saúde a porta de entrada do usuário na unidade básica, se faz necessário verificar se esses profissionais conhecem a espiritualidade e sua relação com saúde, para que este profissional consiga perceber a subjetividade, a espiritualidade do outro, é preciso que tenha consciência de que também é um ser biopsicossocial e espiritual, que necessita autoconhecer-se, descobrir-se, e principalmente aprender a desenvolver a sua espiritualidade. Logo, este profissional se sentirá mais capacitado a ajudar o outro a conviver com os problemas que o envolvem de maneira satisfatória.

A valorização da vida, o cuidado do ser humano do ponto de vista integral e o respeito à individualidade representam aspectos fundamentais na atuação do profissional de saúde, especialmente em um país como o Brasil, caracterizado por um mosaico de traços culturais e representado por uma complexa configuração social. Desse modo, as questões da espiritualidade se inserem de forma importante por serem relevantes para a saúde das pessoas, devendo perpassar as questões de ensino na área da saúde de forma transversal, inserindo-se nas práticas de saúde como princípio de convivência harmoniosa na relação dos profissionais com os pacientes e com a família destes. 
Assim, os profissionais precisam proporcionar um cuidado ao ser humano numa perspectiva holística, valorizando o apoio espiritual, visando a que este possa vivenciar momentos difíceis, com serenidade. Conforme Leloup e Hennezel (2010), espiritualidade é dar um "passo a mais" na aceitação dos próprios limites, como também diante do sofrimento, e ser solidário com quem necessita.

Freire (2005) afirma que o diálogo é fundamentado no amor, na humildade e na fé nos homens se faz uma relação horizontal em que a confiança mútua é consequência óbvia, gerando esperança e transformação. É dentro dessa dimensão que os profissionais envolvidos na Unidade Básica procuram vivenciar a transformação social, acolhendo o indivíduo, respeitando-o em sua autonomia e valorizando-o como cidadão.

Nesse sentido, surgiu o interesse em aprofundarmos conhecimentos envolvendo a temática espiritualidade e a prática do cuidar ao usuário da ESF, com vistas ao desenvolvimento de uma prática mais humana, ética e solidária. Este trabalho envolve um tema bastante complexo, porém busca contribuir, principalmente, para um repensar da prática cotidiana dos profissionais de saúde inseridos na atenção básica, visto que reflete sobre aspectos relacionados à subjetividade humana no processo de adoecimento e de cura.

Esse estudo tem o intuito de analisar a percepção dos profissionais de uma Estratégia Saúde da Família no município de Icó-CE sobre espiritualidade e saúde no cotidiano da atenção básica, assim como conhecer o que os profissionais da ESF percebem como espiritualidade, além de identificar como o conceito da espiritualidade influencia nas praticas profissionais da equipe.

\section{Método}

Trata-se de um estudo explicativo com abordagem qualitativa. O cenário da investigação foi o município de Icó-Ceará, que possui uma população com cerca de 64.456 mil habitantes com distribuição heterogênea entre as zonas rural e urbana, sendo a maior aglomeração na zona urbana (BRASIL, 2010).

Atualmente disponibiliza uma rede de serviços composta por 20 unidades com Estratégia Saúde da Família (ESF). Dentre elas a ESF escolhida para cenário de estudo, pois a mesma abrange diferentes comunidades, sendo zona urbana e rural, foi a Unidade Cidade Nova, localizada na Avenida Manoel Neto Cidade Nova ICÓ-CE, que possuem duas equipes Cidade Nova I e II em uma Unidade que atendem 2603 famílias. A unidade possui dois consultórios de enfermagem, dois consultórios médicos, consultório odontológico, ambulatório, sala de vacinas, farmácia e acolhimento. Oferecendo serviços e procedimentos de enfermagem, médico e odontológico.

Os sujeitos da pesquisa foram 12 profissionais da ESF Cidade Nova. Sendo eles Enfermeiros, Médico, Técnicos de Enfermagem e Agentes Comunitários de Saúde. Como critérios de inclusão 
estabelecidos como componentes da pesquisa foram ter vinculo empregatício e fazer parte da equipe multiprofissional de saúde na Estratégia Saúde da Família Cidade Nova. Já os critérios de exclusão utilizados para realização do estudo era estar ausente durante o período da realização da pesquisa e recusar-se a participar espontaneamente da pesquisa.

Como método de geração de dados, fixamos nossa atenção na utilização da entrevista narrativa (gravada na íntegra), que tem em vista uma situação que encoraje e estimule o entrevistado (chamado de informante) a contar a história sobre algum acontecimento importante de sua vida e do contexto social. Considerada como método de pesquisa qualitativa (JOVCHELOVITCH, 2002; RICOUER, 1997 ; GALVÃO, 1995).

Procurou-se analisar as entrevistas no discurso dito e interdito dos profissionais, através de seis passos (SCHUTZ, 1983), a saber: 1) Transcrição detalhada das expressões verbais dos entrevistados; 2) Divisão do texto em material indexado e não indexado. As proposições indexadas tendo como referência concreta "quem fez o quê, quando, onde e por quê", enquanto que as proposições não indexadas levam em conta os acontecimentos, os valores, juízos e toda forma de uma generalizada "sabedoria de vida"; 3) Uso dos conteúdos indexados do texto, para analisar o ordenamento dos acontecimentos de cada pessoa em suas trajetórias; 4) Investigação das dimensões não indexadas do texto, como "análise do conhecimento"; 5) Compreensão do agrupamento e comparação entre as trajetórias individuais; 6) Comparação de casos e trajetórias individuais, dentro do contexto, e estabelecimento das semelhanças. Este processo nos permitiu a identificação das trajetórias coletivas.

Utilizou-se a cartografia social para organizar o produto final que constitui uma interpretação das entrevistas, reunindo estruturas de relevância dos informantes com as do entrevistador (JOVCHELOVITCH, 2002).

Este processo nos levou a uma relação particular ajudando-nos a ir além de dicotomias estéreis e oposições arbitrárias. A cartografia seria um modo de pensar as coisas instituídas, à sua materialidade própria, às suas formas de auto-organização onde se geram resistências e efeitos perversos, neutralizações e bloqueamentos, autonomia e criatividade. A cartografia veio contemplar a busca de representar, gráfica e teoricamente, as narrativas (JOVCHELOVITCH, 2002).

Cartografar assume, portanto, na análise das entrevistas, uma dupla leitura das narrativas, através daquilo que se denomina de leitura paradigmática e leitura subparadigmática. Neste trabalho, a leitura paradigmática foi compreendida como um meio de enfatizar as complexidades na visão profissionais sobre a saúde e a espiritualidade na Unidade básica de Saúde, na subparadigmática, buscou-se suas formas de interpretação, ligando atores, ações e feitos no tempo. Para comparar, formalmente, cursos particulares e ações (JOVCHELOVITCH, 2002).

Em todas as etapas deste estudo foram observados os aspectos éticos contidos na resolução 466/12 do Conselho Nacional de Saúde (CNS) que regulamenta a pesquisa envolvida envolvendo 
seres humanos, principalmente no que concerne a utilização do Termo de Consentimento Livre e Esclarecido (TCLE), esclarecendo os direitos e deveres a comunidade científica e aos sujeitos da pesquisa, no que diz respeito as quatros referências básicas da bioética: autonomia, não maleficência, beneficência e justiça (BRASIL, 2012). Após autorização por meio da Declaração de Anuência do Secretário Municipal de Saúde de Icó, o projeto foi submetido ao Comitê de Ética em Pesquisa do Instituto Leão Sampaio de Ensino Universitário Ltda, para apreciação e autorização para a realização da pesquisa.

\section{Resultados e Discussão}

\section{Descrevendo os sujeitos da pesquisa}

Tabela 1 - Caracterização dos sujeitos da pesquisa segundo sua Categoria Profissional, Sexo, Unidade de Saúde que atua.

\begin{tabular}{clcc}
\hline Profissional & \multicolumn{1}{c}{ Formação } & Sexo & ESF \\
\hline $\mathrm{P}_{1}$ & Enfermagem & $\mathrm{F}$ & Cidade Nova I e II \\
\hline $\mathrm{P}_{2}$ & Enfermagem & $\mathrm{F}$ & Cidade Nova I e II \\
\hline $\mathrm{P}_{3}$ & Medicina & $\mathrm{F}$ & Cidade Nova I e II \\
\hline $\mathrm{P}_{4}$ & Técnico de Enfermagem & $\mathrm{F}$ & Cidade Nova I e II \\
\hline $\mathrm{P}_{5}$ & Técnico de Enfermagem & $\mathrm{F}$ & Cidade Nova I e II \\
\hline $\mathrm{P}_{6}$ & Técnico de Enfermagem & $\mathrm{F}$ & Cidade Nova I e II \\
\hline $\mathrm{P}_{7}$ & ACS & $\mathrm{F}$ & Cidade Nova I e II \\
\hline $\mathrm{P}_{8}$ & ACS & $\mathrm{F}$ & Cidade Nova I e II \\
\hline $\mathrm{P} 9$ & ACS & $\mathrm{F}$ & Cidade Nova I e II \\
\hline $\mathrm{P} 10$ & ACS & $\mathrm{F}$ & Cidade Nova I e II \\
\hline $\mathrm{P} 11$ & ACS & $\mathrm{F}$ & Cidade Nova I e II \\
\hline $\mathrm{P} 12$ & ACS & $\mathrm{F}$ & Cidade Nova I e II \\
\hline
\end{tabular}

Fonte: dados da pesquisa

A amostra constou de 12 Profissionais de saúde, sendo todos do sexo feminino. Atualmente vemos uma nova ótica na saúde brasileira, onde as mulheres tem se colocado em vários patamares e tem sido focalizada em vários prismas, uma vez que assumiu um papel de emancipação e de igualdade para com a classe masculina.

Com base nos discursos e experiências dos profissionais, abordaremos seus relatos e desabafos, separando por categorias e fazendo um comparativo á luz da literatura, a partir das categorizações a seguir:

\section{Espiritualidade $x$ Saúde}

As narrativas dos profissionais faz-nos perceber traços factuais vividos ou uma cultura inserta na prática social de cada um deles. Vejamos o que nos ensina acerca da visão sobre espiritualidade e 
saúde, diante de uma profissional escutada, aos 34 anos de idade: "quando as duas andam juntas o resultado é bem melhor, pois tudo depende de como o seu espírito está, se há confiança, se há fé, pois muitas vezes não há doença e sim algo interior, ou seja, as vezes não é algo no corpo e sim na alma".

A narradora faz um parâmetro entre espiritualidade e saúde, relacionando a alma e ao espírito, supervalorizando a fé. Seu discurso é linear. O profissional reconhece a relação entre ambas, e nos mostra que em alguns casos não se faz necessário um tratamento medicamentoso, mas sim uma conversa, no intuito de desabafar seus sentimentos e angustias vividas.

Como diz Vasconcelos, (2006) apontando que a espiritualidade traduz-se em sermos seres espirituais e possuirmos, transitoriamente, um corpo físico. Onde pesquisas realizadas pelas ciências naturais, como a física e a biologia, têm endossado essa afirmação. O corpo físico é apenas um reflexo do espírito. Assim, a espiritualidade é algo inerente ao ser humano. Constitui campo de elaboração subjetiva no qual a pessoa constrói de forma simbólica o sentido de sua vida e busca fazer frente à vulnerabilidade desencadeada por situações que apontam para a fragilidade da vida humana.

Horta (2003), após estudar o sentido da palavra saúde, estabeleceu as bases para o entendimento da relação entre saúde e fé cristã. A partir da bioética, fez uma leitura da realidade do mundo da saúde. Usando o diabetes como fonte de experiência, aponta a vivência da fé e da espiritualidade como motivadora de troca de experiência e de desejo de conversão.

Outro depoimento, dentre os muitos realizados em nossa pesquisa, foi de uma profissional de 50 anos de idade "a espiritualidade é a questão da alma, pois Jesus é a essência de tudo isso, nos trazendo paz interior em meio às dificuldades do dia a dia, fazendo com que o ser humano possa ter uma boa qualidade de vida".

P10- "O bem estar espiritual traz conforto e qualidade de vida".

Para Boff (2011), aponta a espiritualidade como uma das fontes primordiais, de inspiração do novo, de esperança, de geração de um sentido de plenitude e de capacidade de autotranscendência do ser humano. Para o autor a espiritualidade, é tudo aquilo que vem produzir dentro do ser humano uma mudança. Ele vem afirmar que na atualidade a espiritualidade vem sendo uma descoberta como uma dimensão profunda do ser humano e como um espaço de paz no meio de conflitos existenciais. Ressaltando a experiência de Jesus enquanto espiritualidade profunda e como as verdadeiras pilastras que ate hoje sustentam o cristianismo como caminho espiritual.

Ainda na mesma vertente, vemos agora a fala de uma terceira profissional de 35 anos de idade "independente da religião, o importante é que você tenha espiritualidade, pois ela traz mudança e fé, conforme sua religião".

Vemos que ainda há uma confusão quanto falamos de religião e espiritualidade, no entanto as duas são distintas.

76 Id en line Revista de Psicologia. Ano 9, No. 26, Supl. Esp. Abril/2015 - ISSN 1981-1179. Edição eletrônica em http://idonline.emnuvens.com.br/id 
Boff (2011) aponta diferenças entre religião e espiritualidade, na qual a primeira esta associada a crenças dogmas e rituais, e a segunda relacionada às qualidades do ser humano, como a compaixão, amor, capacidade de perdoar, solidariedade, harmonia, tolerância e noção de responsabilidade, trazendo felicidade para a própria pessoa e para os outros.

Ao abordar se a espiritualidade e a saúde estão interligadas, vemos o depoimento de um profissional de 34 anos de idade "com certeza, pois tudo gira em torno de como o meu espírito esteja, por que assim, eu vou poder enfrentar as dificuldades e os desafios, ou seja, tudo isso nos ajuda na cura e a cura de um paciente passa por todos esses meios, medicação, intuição, cuidado, fé e espiritualidade."

P03- "Sem espiritualidade não há saúde".

P04- "A espiritualidade é algo no nosso interior, no espirito".

Segundo Horta (2003), o ato de saúde precisa ser um ato de cuidado dirigido, também, à dimensão espiritual do paciente. É preciso agregar ao saber científico, intuição, emoção e acuidade de percepção sensível, além da razão. A autora também relata que diante uma doença, muitas vezes, manifestam-se, no paciente, sentimentos de medo e angústia, os quais devem ser identificados, respeitados e tratados. Não propomos um discurso religioso, pois o respeito à crença de cada pessoa é indiscutível, como preveem tanto a espiritualidade quanto a bioética.

A autora traz como proposta o acolhimento abrangente, como qual podemos demonstrar amor e interesse pela sua vida. Esse cuidado mais abrangente do que somente tratar o corpo pode estar incluso nas tarefas da equipe multiprofissional, de uma unidade básica de saúde principalmente, porque a mesma tem mais contato com o paciente do que o profissional que exerce a função de assistente espiritual. Sendo o cuidado espiritual importante. Esse cuidado não supõe um tempo específico, mas se faz presente na relação, na maneira do profissional estar presente, ouvir, orientar e exercer técnicas junto ao paciente (HORTA, 2003).

\section{Espiritualidade na Unidade Básica de Saúde.}

O campo de estudo da atenção primaria é muito vasto, pois o mesmo assiste e acompanha famílias, sendo um ambiente de troca de saberes e experiências.

Em seu discurso a ACS de 50 anos de idade traz "muitas vezes as pessoas vem ao posto não em busca de um remédio, mas em busca de um apoio, um conselho, por isso o profissional deve estar capacitado para poder dar uma injeção de animo nessa pessoa." É importante que esses profissionais estejam bem consigo mesmos, para assim poderem ajudar ao outro, fazendo com esses pacientes um 
resgate da espiritualidade através do dialogo, onde será possível a expressão e o desabafo dos sofrimentos e angustias.

Teixeira (2006), em seu estudo escreveu sobre a reumanização do trabalho dos profissionais da unidade básica de saúde com enfoque na dimensão espiritual. As autoras observaram que a desconsideração à dimensão espiritual humana ocasiona prejuízos ao desenvolvimento do capital humano em serviços de saúde. Apontaram novos paradigmas de administração relacionados à evolução da espiritualidade. Considerando que a dimensão espiritual tem uma natureza sistêmica e que, através da ética e estética, harmoniza todas as dimensões do homem em seus relacionamentos com outros, as autoras abordaram a dimensão espiritual como fundamental para a reumanização do trabalho na unidade básica de saúde. Elas recomendaram a integração da dimensão espiritual ao trabalho diário desses profissionais como um fator determinante para sua atuação assim como um indutor para uma melhor qualidade de vida pessoal e profissional.

Em um desabafo vemos o discurso de uma ACS 30 anos de idade "o ACS deve ser um pouco de tudo, eu não me preocupo com a quantidade de minhas vizitas e sim na qualidade delas, e muitas vezes me deparo com cada situação”. Por estarem em contato direto com a população a ACS tem respaldo para expressar diversas experiências nesse âmbito.

Boff (2011) estudou a espiritualidade e o cotidiano das agentes comunitárias de saúde, de forma a repensar a educação em saúde junto às classes populares. Examinou a questão da espiritualidade popular à luz de uma conjuntura de exclusão social e em sua relação com os processos de educação popular em saúde desenvolvidos no âmbito dos serviços do SUS, a fim de propor que esta questão seja incorporada na metodologia de trabalho de educação em saúde com as classes populares urbanas.

Nesse estudo o autor contribui para que o profissional de saúde possa ter uma maior compreensão sobre como pensam a saúde e doença os grupos populares. O autor constatou que o fenômeno da religiosidade/espiritualidade, expresso através de estratégias e práticas cotidianas, está presente na forma como os grupos populares veem e lidam com os seus problemas de saúde. Este é um fenômeno que necessita maior compreensão no âmbito da Educação em Saúde que possui como perspectiva o fortalecimento da participação popular.

Em outra vertente vemos o discurso de uma Enfermeira de 28 anos de idade "pessoas que buscam espiritualidade são mais saudáveis, conseguem passar com mais facilidade pelos problemas da vida”. Em seu desabafo vimos que em sua rotina de trabalho a profissional comprovou a eficácia da espiritualidade como escape para as diversas situações da vida.

P01- "Precisamos da espiritualidade para enfrentar as situações do dia a dia". 
Em seu estudo Saad et al., (2001) fizeram uma revisão na literatura a qual intitularam Espiritualidade baseada em evidências. Definiram espiritualidade como um sistema de crenças que enfoca elementos intangíveis, que transmite vitalidade e significado a eventos da vida. Tal crença pode mobilizar energias e iniciativas extremamente positivas, com potencial ilimitado para melhorar a qualidade de vida da pessoa. Observaram que as implicações da espiritualidade na saúde vêm sendo estudadas cientificamente e documentadas em centenas de artigos.

\section{Paciente Terminal e Espiritualidade.}

O cuidado espiritual ao paciente terminal caracteriza um desafio. Supõe formação, maturidade, habilidade, serenidade e sensibilidade às reais necessidades do outro.

Quando indagamos sobre as experiências, em seu discurso vemos agora a Técnica de Enfermagem, 34 anos de idade "tenho algumas experiências, uma vez me deparei com a seguinte situação: Eram dois pacientes em estado terminal, porem um tinha espiritualidade, fé e confiança, ele confiava que o amanha iria ser bem melhor. Já o outro não tinha fé nem confiança, estava sempre triste e pensando na morte. São duas realidades diferentes, porem o paciente que tinha espiritualidade conseguiu viver mais e com mais qualidade de vida, já o que não tinha morreu bem mais rápido. Mas eu não sabia o que fazer diante dessa situação”.

Para que o paciente terminal possa receber um cuidado completo na fase final de sua vida, é preciso haver sincronia entre estas áreas do conhecimento e ação. Também, não é possível desvincular os papéis dos diferentes atores em saúde. Portanto, as ações dos profissionais estão interligadas e traduzem processos de trabalho em formas de produção coletiva de saúde. A bioética e a espiritualidade constituem ferramentas no sentido de ajudarem a ultrapassar a ideia curativa da saúde e voltar-se para a potencialização do sujeito visto em suas múltiplas dimensões (DURAND, 1995).

P07- "Só alguém com a espiritualidade elevada pode lidar com a questão do processo de morte e morrer".

Segundo Barchifontaine, (2000) na terminalidade, muitas vezes, manifestam-se, no paciente, sentimentos de medo e angústia, os quais devem ser identificados, respeitados e tratados pelos profissionais de saúde.

Não propomos um discurso religioso, pois o respeito à crença de cada pessoa é indiscutível, como preveem tanto a espiritualidade quanto a bioética. Para o autor esse cuidado mais abrangente do que somente tratar o corpo pode estar incluso nas tarefas dos profissionais da unidade básica de saúde, principalmente, porque a mesmos tem mais contato com o paciente do que o profissional que exerce a função de assistente espiritual. Sendo o cuidado espiritual importante, os profissionais devem se 
instrumentalizar para integrá-lo em sua atividade diária. Esse cuidado não supõe um tempo específico, mas se faz presente na relação, na maneira do profissional de estar presente, ouvir, orientar e exercer técnicas junto ao paciente.

P10- "Muitas vezes não sei o fazer quando vejo um paciente perto de morrer."

Destacamos um fator que dificulta o cuidado espiritual, que é a influência do materialismo por valorizar sobremaneira a beleza, o poder, e o material, desse modo, esvaziando o ser humano do valor que ele tem em si, como ser único, inteligente, livre, responsável e digno. Este aspecto tem reflexos na atuação dos profissionais de saúde que exercem sua profissão junto a pessoas fragilizadas, como é o caso dos pacientes terminais.

A dimensão espiritual formará um novo paradigma social. Cada vez mais se reconhece que a fé ajuda no processo de recuperação da saúde e enfrentamento da doença. A espiritualidade beneficia a saúde integral da pessoa e capacita o profissional a lidar com o paciente. Os profissionais, no geral, não estão preparados para prestar o cuidado espiritual ao paciente terminal. Este cuidado implica um processo pessoal de autoconhecimento e amadurecimento, uma experiência de fé significativa (VASCONCELOS, 2006).

P12- "Os profissionais de saúde precisam antes de tudo ser seres espiritualizados, para assim poderem ajudar seus pacientes".

Para Durand, 1995. espiritualidade é definida como uma conexão sistêmica com Deus, a natureza ou outro ser humano e o sentido encontrado nesta relação. A chave para o cuidado espiritual é estabelecer um equilíbrio entre o controle dos sintomas físicos e a espiritualidade; este equilíbrio é construído através da história individual de cada paciente, seus valores e necessidades. Os autores apresentaram um estudo de caso e mostraram a importância de se controlar os sintomas no processo de morrer. Apesar disto, é benéfico se ampliar o foco dos cuidados ao paciente terminal, inserindo-se a questão da espiritualidade, o que resulta em uma melhor autoaceitação do paciente, reconciliação com a família e a restauração da saúde emocional.

De acordo com os autores, os profissionais da unidade básica de saúde devem estar habilitados para equilibrar o controle dos sintomas e a questão da espiritualidade, de acordo com o desejo do paciente, no tratamento em fase terminal.

Entre vocês há alguém que está doente? Que ele mande chamar os presbíteros da igreja, para que estes orem sobre ele e ungem-no com óleo, em nome do Senhor. E a oração feita com fé curará o doente; o Senhor o levantará. E se houver cometido pecados, ele será perdoado. Portanto, confessem os seus pecados uns aos outros e orem uns pelos outros para serem curados. A oração de um justo é poderosa e eficaz (BIBLIA, 2010). 


\section{Conclusões}

O presente estudo mostrou que é preciso vocação, dedicação, treinamento e uma experiência de vida para incluir, no cuidado ao paciente na dimensão espiritual. Realizando um resgate da espiritualidade, respeitando suas crenças e agindo com bioética.

É necessário humanizar e resgatar os valores subjetivos. Todos os entrevistados viram a importância de incluir o cuidado espiritual às tarefas técnicas prestadas ao paciente, pois são os profissionais da unidade básica que estão em constante contato com o paciente. O cuidado espiritual é permanecer sensíveis e abertos para falar aquilo que sentimos ser o melhor para o paciente e sua família. É nessa relação que encontramos e descobrimos a forma e o momento correto de falar, como falar e o que falar.

No entanto, muitos não sabem diferenciar a espiritualidade da religiosidade, algo que é de extrema importância, pois as mesmas são distintas e causam inúmeras discussões. Por isso o profissional deve ser imparcial, respeitar as crenças e individualidades de cada paciente, no entanto, para tal, esse profissional deve ser conhecedor da espiritualidade e de seus benefícios.

O ambiente da unidade básica de saúde nos traz um lugar favorável ao dialogo e troca de experiências, que alguns sujeitos reconhecem quando relatam suas vivencias, no entanto o enfrentamento de doenças e dificuldades sofridas pelos pacientes, ainda são um terreno amplo de discussões para esses profissionais. Pois, como aconselhar e dialogar dessas dificuldades se os próprios profissionais não sabem como enfrenta-las. Para resgatar a espiritualidade de pacientes e da sua família, também é necessário ser um profissional espiritual.

Neste sentido, as questões da espiritualidade se inserem de forma importante por serem relevantes para a saúde das pessoas, devendo perpassar as questões de ensino na área da saúde de forma direta, inserindo-se nas práticas de saúde como princípio de convivência harmoniosa na relação dos profissionais com os pacientes e com a família destes.

Sendo assim, espera-se que esse estudo venha contribuir para a melhoria no atendimento e na qualidade de vida dos pacientes assistidos na unidade básica de saúde, trazendo novos conhecimentos, e mostrando a importância da espiritualidade inserida nesse contexto, no intuito de oferecer uma visão ampla aos profissionais nessa temática, trazendo benefícios para os mesmo e para os pacientes.

\section{Referências}

BARCHIFONTAINE CP. Problemas atuais de bioética. 5a . ed. São Paulo: Loyola, 2000.

BRASIL, A Implantação da Unidade de Saúde da Família. Brasília, Ministério da Saúde, 2010. 
Ministério da Saúde. Comitê Nacional de Educação Popular em Saúde (CNEPS).

BOFF, L. Espiritualidade: um caminho de transformação. 6. ed. Editora: Sextante, 2001. 94p.

Espírito e saúde. 1 ed . Editora: Petrópolis, 1997. 21-28p.

BOFF, L. Tempo de transcendência: o ser humano como um projeto infinito. $1^{\circ}$ ed. Editora: Sextante, 2000. 93p.

DURAND G. A bioética: natureza, princípios objetivos. Trad. Porphírio Figueira de Aguiar Netto. São Paulo: Paulus, 1995.

FREIRE, P. Pedagogia do oprimido. 42. ed. Rio de Janeiro: Paz e terra, 2005a. 213p.

Educação e mudança. 28. ed. Rio de Janeiro: Paz e terra, 2005b.

GALVÃO, C. Narrativas em educação. Ciência \& Educação, Bauru, v. 11, n. 2, p. 327-345, 1995.

HORTA CR, . O papel da fé no enfrentamento do câncer. São Paulo: Roma; 2003.

JOVCHELOVITCH, S. Vivendo a vida com os outros. Intersubjetividade, espaço público e representações sociais. In: GUARESCH P.; JOVCHELOVITCH, S. Textos em representações sociais. Petrópolis: Vozes, 2002.

KOENIG, H.G. Espiritualidade no cuidado com o paciente: por que, como, quando e o quê. $1^{\circ}$ ed. Editora Jornalística, 2010.

LAKATOS, EM. Fundamento de metodologia cientifica. $7^{\circ}$ ed. São Paulo: Atlas, 2010.

LELOUP, J. Y. HENNEZEL, M. A arte de morrer: todo homem é espiritual. 6.ed.

Petrópolis: Vozes, 2010.

RICOUER, P. Tempo e narrativa. São Paulo: Papirus, 1997.

SAAD, M.; MASIERO, D.; BATTISTELLA, L. Espiritualidade baseada em evidências. $1^{\circ}$ ed. Edidora: Acta Fisiátrica, 2001.

SCHUTZ, A. Collected Papers. . IV Edição. Dordrecht: Kluwer. 1983.

TEIXEIRA, F. Os caminhos da espiritualidade: um olhar com base nas tradições místicas. 2010.

VOLCAN, S.M.A. - Relationship between spiritual well-being and minor psychiatric disorders: a cross-sectional study. Rev. Saúde Pública,v.4, n.2, p6, 2003.

VASCONCELOS, E. M. (org.). Espiritualidade no trabalho em saúde. São Paulo:

Hucitec, 2006.

Como citar este artigo (Formato ABNT):

BARROS JÚNIOR, J; BARBOSA, R.S.; LUNA NETO, R.T.; TAVARES, N.B.F.; FREITAS, K.M.; CRUZ, C.A.; MOURA, U.H.S. Saúde e Espiritualidade: As narrativas profissionais na estratégia Saúde da Família. Id on Line Revista de Psicologia, Abril de 2015, vol.9, n.26, Sup. Esp. p. 71-82. ISSN 1981-1189. 